Proceedings

\title{
Inclusion Complex of Iloperidone with Sulfobutyl Ether Beta- Cyclodextrin: Characterization and Dissolution Studies ${ }^{\dagger}$
}

\author{
Rupali Bhadale and Vaishali Londhe*
}

SVKM's NMIMS, Shobhaben Pratapbhai College of Pharmacy \& Technology Management, V. L. Mehta Road, Vile Parle(W), Mumbai 400056, India; rupalibhadale5@gmail.com

* Correspondence: Vaishali.Londhe@nmims.edu; Tel.: +91-981-901-7415

+ Presented at the 1st International Electronic Conference on Pharmaceutics, 1-15 December 2020; Available online: https://iecp2020.sciforum.net/.

\begin{abstract}
Iloperidone (ILO) is a second-generation antipsychotic drug and a first-line treatment approved by USFDA in May 2009. Iloperidone belongs to Biopharmaceutical Classification Systems (BCS) class II; thus, it is poorly water-soluble, highly permeable, and has $\mathrm{pH}$-dependent solubility. Cyclodextrins and their derivatives have a wide range of applications in different formulations due to their complexation ability, which improves the solubility, stability, safety, and bioavailability of a drug. We have tried the complexation of iloperidone with sulfobutyl ether- $\beta$-cyclodextrin $(\mathrm{SE} \beta \mathrm{CD})$ to improve its solubility and dissolution. Complexation was done by the kneading method. The characterization of the SE $\beta C D$ complexes with Iloperidone was done by FTIR, differential scanning calorimetry (DSC), saturation solubility, etc. A multimedia dissolution of the complex was carried out and compared with the plain drug. A significant improvement in drug release was found from SE $\beta C D$ complexes in all media when compared with the drug alone.
\end{abstract}

Keywords: $\beta$-cyclodextrin; binary complex; antipsychotic drug; dissolution studies

\section{Introduction}

Drug solubility is a crucial element for a safe and efficacious formulation, as the absorption and bioavailability depend on its solubility. Furthermore, to display its efficacy, a drug molecule desires water solubility and permeability, which may be absorbed in the site of action. More than $90 \%$ of new chemical molecules have low water solubility [1]. Several techniques can be used to boost the solubility, like chemical and physical techniques. Cyclodextrin is widely used to enhance drug solubility by altering the physicochemical properties of the drugs [2]. Cyclodextrin forms the inclusion complex with guest molecules by fitting in their cavity, which satisfies the structural specifications and forces required to form a complex [3,4]. The inclusion complexes showed improved drug absorption, rapid drug release, and decreased side effects [5]. The cyclodextrin-based inclusion complex with the lipophilic drug has risen to a high position in the pharmaceutical field, as it can alter the physicochemical properties of drugs [6]. These amendments have an imperious part in drug delivery.

Iloperidone (ILO) is an atypical antipsychotic drug used to treat schizophrenia approved by USFDA in May 2009 [7]. Schizophrenia is a chronic and severe mental disorder affecting more than 20 million individuals globally. ILO is a potent drug, as it shows better activity in a comparatively lower dose (12-16 mg) and acts as a dopaminergic and serotonergic antagonist. Tablets of ILO exist in several strengths, ranging from $1 \mathrm{mg}$ to $12 \mathrm{mg}$. Moreover, it has less affection for the histamine and its receptor, the lowest sedation-related complications, and substantial progress in extrapyramidal symptoms [8-10]. ILO is a Biopharmaceutical Classification Systems (BCS) class II drug with low solubility and high permeability. 
This work aimed to prepare a complex with sulfobutyl ether- $\beta$-cyclodextrin (SE $\beta C D)$ to improve solubility and dissolution, consequently enhancing bioavailability. The inclusion complex was characterized by saturation solubility, FTIR, differential scanning calorimetry (DSC), and multimedia dissolution.

\section{Experiments}

\subsection{Materials}

ILO and SE $\beta C D$ were a kind gift from Symed Labs, Hyderabad, and Cyclolab. Purified water, analytical grade reagents, and chemicals were used to prepare the solution.

\subsection{Method}

\subsubsection{Phase Solubility Studies}

Higuchi and Connors defined the method used to perform the phase solubility studies for ILO with SE $\beta C D$. A UV spectrophotometer analyzed the samples at $229 \mathrm{~nm}$. Complexation efficiency (CE) is the solubility of guest molecules by cyclodextrin (Equation (1)). The effect of cyclodextrin on solubility was analyzed from the solubility graph. The stability constant $(\mathrm{Kc})$ was calculated from the ILO solubility graph in water (Equation (2)).

An equation:

$$
\mathrm{CE}=\frac{\text { Slope }}{(1-\text { slope })}
$$

where CE is complexation efficiency.

$$
\mathrm{K}_{\mathrm{C}}=\frac{\text { Slope }}{\text { S0 (1-slope })}
$$

where $\mathrm{K}_{\mathrm{c}}$ is stability constant and $\mathrm{S}_{0}$ is the solubility of ILO only.

\subsubsection{Formulation of the Solid Inclusion Complex}

The kneading method was used to prepare the inclusion complex, which provides maximum solubility [11]. The drug and SE $\beta C D$ were calculated precisely in a ratio of 1:1. A uniform paste of SE $\beta C D$ was formulated in the mortar by adding an adequate portion of methanol:water (1:1) followed by the addition of ILO, with continuous kneading for 45 min. The suitable paste consistency was maintained by adding a sufficient quantity of methanol:water (1:1). The complex was dried using a preheated hot air oven at $55{ }^{\circ} \mathrm{C}$ for $6 \mathrm{~h}$. The dried complex was crushed, passed through sieve no. 44, and kept in a sealed container [12].

\subsection{Characterization of the Solid Inclusion Complex}

\subsubsection{Saturation Solubility}

The solid inclusion complex's saturation solubility was analyzed by adding an extra quantity of inclusion complex to achieve a steady state in a conical flask containing $10 \mathrm{~mL}$ phosphate buffer ( $\mathrm{pH}$ 6.8), acetate buffer ( $\mathrm{pH} 4.5$ ), and $0.1 \mathrm{~N} \mathrm{HCl}$ buffer. The conical flasks containing various solvents were kept in an orbital shaker for $24 \mathrm{~h}$ at $100 \mathrm{rpm}$ at ambient temperature. After reaching the steady state, the sample was filtered through a $0.45 \mu \mathrm{m}$ syringe filter and analyzed spectrophotometrically at $229 \mathrm{~nm}$ [11].

\subsubsection{Drug Content}

The $10 \mathrm{mg}$ equivalent solid inclusion complex was weighed accurately and dispersed in methanol. Subsequently, it was subjected to an orbital shaker for an hour to confirm the complete extraction of ILO. It was then filtered and estimated spectrophotometrically at $229 \mathrm{~nm}$. 
2.3.3. Attenuated Total Reflection-Fourier-Transform Infrared Spectroscopy (ATR-FTIR)

The FTIR of ILO, SE $\beta C D$, and the inclusion complex was analyzed using the ATRFTIR spectrometer (Perkin Elmer) at a broad range of $4000-400 \mathrm{~cm}^{-1}$. The sample was kept at the diamond substrate, and the pressure was applied with a compression bar. The software converts the ATR to absorbance. The characteristic peaks were analyzed compared with ILO and SE $\beta C D$ to check the interaction between them.

\subsubsection{Thermal Analysis}

The thermal analysis of ILO, SE $\beta C D$, and the inclusion complex was studied using Mettler Toledo's DSC. An empty aluminum plate was used as a reference. Around $5 \mathrm{mg}$ of each test sample were pursed in an aluminum plate, and thermograms were found under a nitrogen gas flow of $10 \mathrm{~mL} / \mathrm{min}$. The thermal analysis was conducted at a heating rate of $10{ }^{\circ} \mathrm{C} / \mathrm{min}$ from $30-300{ }^{\circ} \mathrm{C}$.

\subsubsection{Multimedia Dissolution Study}

An in-vitro analysis of ILO and the inclusion complex (in capsule shell) was carried out using Dissolution apparatus USP Type II (Paddle type) (Electrolab, India). A phosphate buffer ( $\mathrm{pH} 6.8)$, acetate buffer ( $\mathrm{pH} 4.5)$, and $0.1 \mathrm{~N} \mathrm{HCl}$ buffer $(500 \mathrm{~mL})$ were used as dissolution media at $37 \pm 0.5^{\circ} \mathrm{C}$ at $50 \mathrm{rpm} .10 \mathrm{~mL}$ aliquot of dissolution media was taken at pre-determined time intervals. The drug release profile of ILO and the inclusion complex were studied and compared to check the release of drug in multimedia.

\section{Results and Discussion}

\subsection{Experimentals}

\subsubsection{Phase Solubility Studies}

The phase solubility studies are a crucial parameter during the development of the inclusion complex with the drug. The drug's (ILO) solubility curve in aqueous SE $\beta C D$ was carried out, which showed that ILO's solubility improved linearly, with an increase in the concentration of SE $\beta C D$. ILO showed an AL-type graph, demonstrating the firstorder dependency of the interaction with SE $\beta C D$. The linear AL-type of the solubility curve suggests a 1:1 ratio for the complexation of ILO and SE $\beta C D$ (Figure 1, Table 1). The higher value of $\mathrm{CE}$ and $\mathrm{K}_{\mathrm{C}}$ specifies the stable formation of the complex by interacting with SE $\beta C D$. Kim et al. showed an enhanced intrinsic solubility, resulting in an improved $\mathrm{CE}$ in the presence of SE $\beta C D$ by forming salt [13].

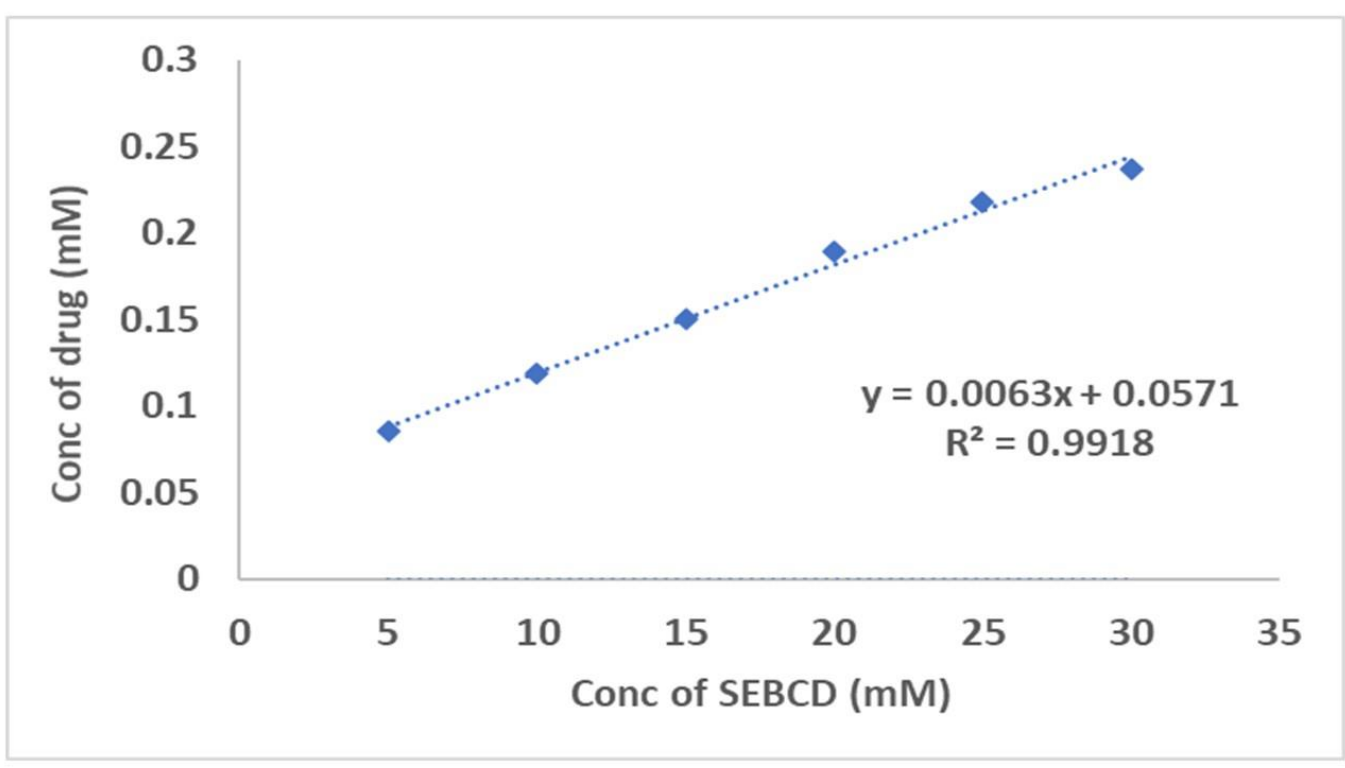


Figure 1. Solubility curve of Iloperidone (ILO):sulfobutyl ether- $\beta$-cyclodextrin (SE $\beta C D$ ) in water $($ Mean $\pm \mathrm{SD})$.

Table 1. Phase solubility studies of the inclusion complex.

\begin{tabular}{cc}
\hline Parameters & Observation \\
\hline Slope & 0.0063 \\
$\mathrm{R}^{2}$ & 0.9918 \\
$\mathrm{y}$-intercept $\left(\mathrm{S}_{0}\right)$ & 0.051 \\
$\mathrm{~K}_{\mathrm{c}}\left(\mathrm{M}^{-1}\right)$ & 124.31 \\
$\mathrm{CE}$ & 0.0063 \\
\hline
\end{tabular}

\subsubsection{Saturation Solubility and Drug Content}

The saturation solubility of ILO and the inclusion complex in a phosphate buffer ( $\mathrm{pH}$ 6.8), acetate buffer ( $\mathrm{pH} 4.5)$, and $\mathrm{HCl}$ buffer is represented in Figure 2 . The improved solubility of ILO in multimedia compared with plain ILO resulted from the inclusion complex of ILO and SE $\beta C D$. The percent drug content was found to be $99.23 \pm 0.49$, which complies with specifications.

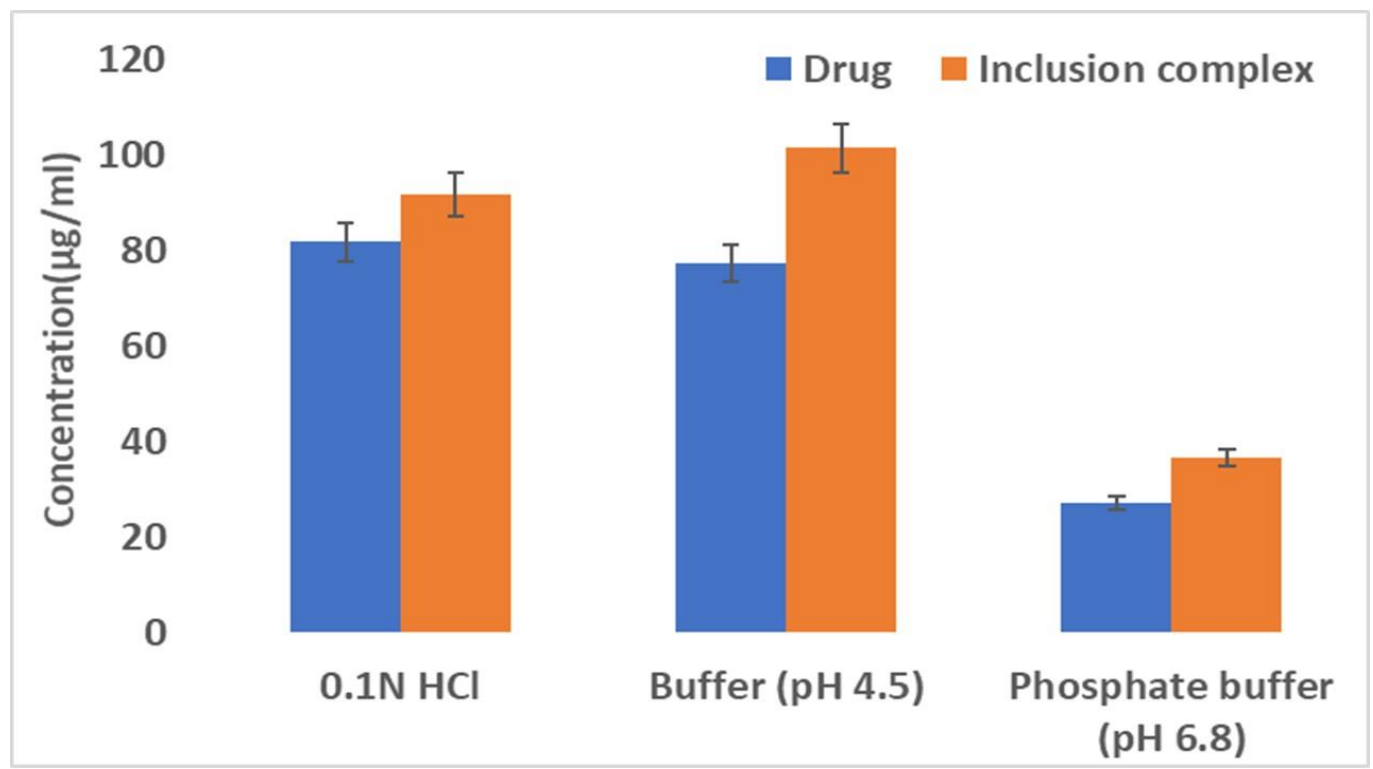

Figure 2. Multimedia saturation solubility of the drug and the inclusion complex (Mean $\pm S D, n=$ $3)$.

\subsubsection{ATR-FTIR}

ATR-FTIR is a convenient method to evaluate the drug (guest) and SE $\beta C D$ (host) solid-state interaction. In IR spectra, detected peaks describe distinct functional groups that may change or modify the intensity of contacting host molecules by forming an inclusion complex, signifying effective complexation [14]. The ATR-FTIR spectra displayed $\mathrm{C}-\mathrm{F}$ stretch at $1262 \mathrm{c} \mathrm{m}^{-1}, \mathrm{~N}-\mathrm{O}$ stretching at $1352 \mathrm{~cm}^{-1}, \mathrm{C}=\mathrm{O}$ stretching at $1668 \mathrm{~cm}^{-1}$, and $2949 \mathrm{~cm}^{-1}$ due to C-H stretching vibration. The spectrum of SE $\beta C D$ is mainly characterized at $\sim 1644 \mathrm{~cm}^{-1}$ and reflects the $\mathrm{H}-\mathrm{O}-\mathrm{H}$ stretching of water molecules, whereas the peaks at $\sim 1153 \mathrm{~cm}^{-1}$ and $\sim 1032 \mathrm{~cm}^{-1}$ are attributed to C-H and C-O stretching vibrations. The IR spectra of the inclusion complex depicted a decrease in intensity, the alteration, and the disappearance of some distinctive IR bands of ILO. The interaction of ILO with SE $\beta C D$ was confirmed by a significant shift of some distinctive bands of ILO (Figure 3). 


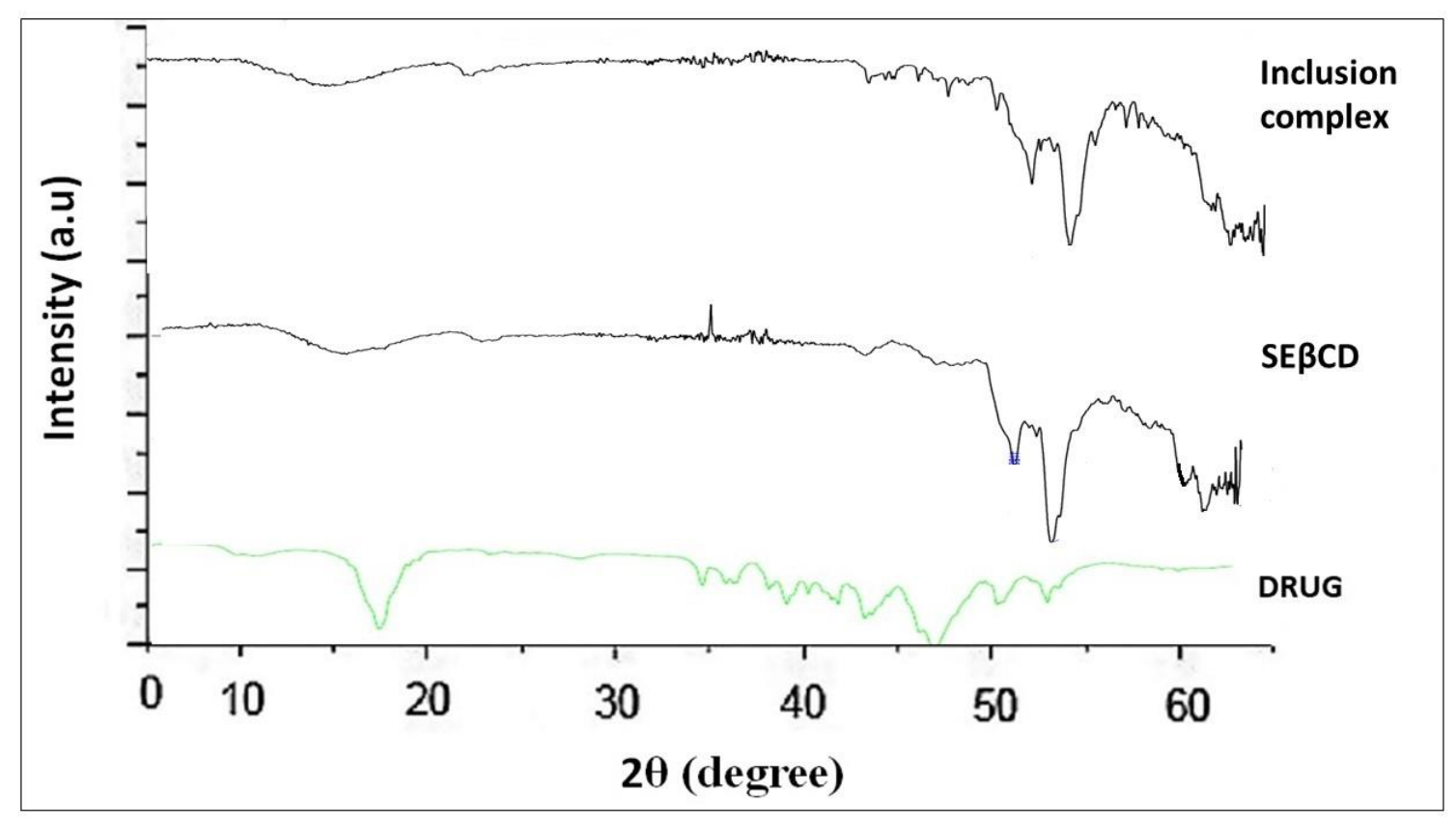

Figure 3. FTIR spectra of the drug (ILO), SE $\beta C D$ and the inclusion complex.

\subsubsection{Thermal Analysis}

Thermal analysis delivers additional suggestions for forming the inclusion complex due to the melting or decay of drugs that may shift to different temperatures or disappear when formulated with SE $\beta C D$ [15]. The thermogram of ILO, SE $\beta C D$, and the inclusion complex is shown in Figure 4. The DSC of ILO displayed a sharp and well-defined endothermic peak at $120^{\circ} \mathrm{C}$, conforming to the drug's (ILO) melt point. In the endotherm of $\mathrm{SE} \beta \mathrm{CD}$, a broad peak was detected at $86^{\circ} \mathrm{C}$. The endotherm of ILO utterly disappeared into the stable inclusion complex. The amorphization of the drug describes an enhancement in the dissolution profile of ILO.

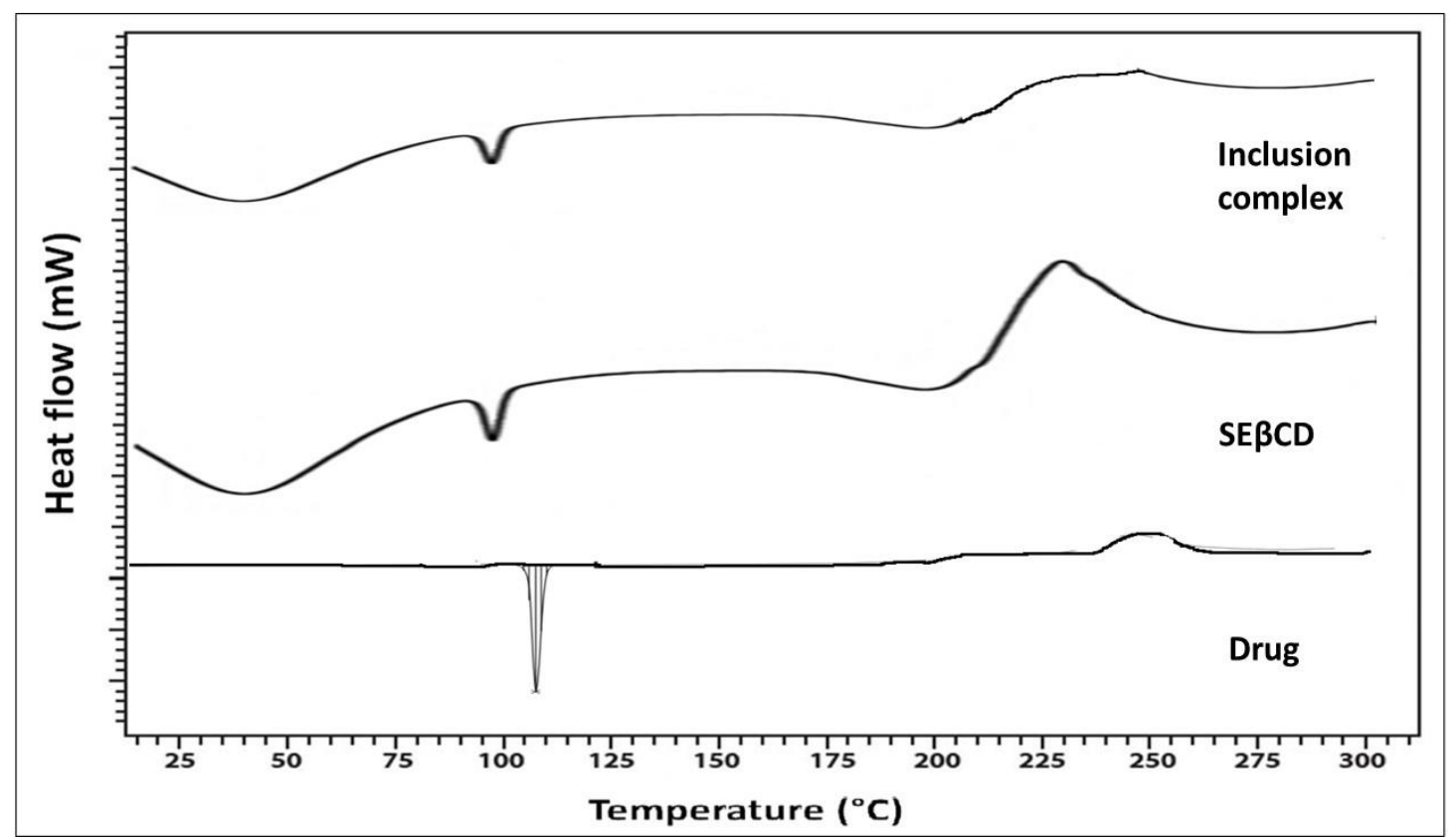

Figure 4. DSC thermogram of the drug (ILO), SE $\beta C D$ and the inclusion complex.

3.1.5. Multimedia Dissolution Study 
The dissolution study was analyzed to examine the enhanced solubility of ILO from the inclusion complex. The multimedia dissolution of the inclusion complex was done to identify the behavior of the complex over a wide range of $\mathrm{pH}$. The dissolution of the inclusion complex and ILO was done in a $0.1 \mathrm{~N} \mathrm{HCl}$ buffer, acetate buffer ( $\mathrm{pH} 4.5)$, and phosphate buffer ( $\mathrm{pH} 6.8$ ), shown in -c) respectively. More than $80 \%$ of the drug release was found in $0.1 \mathrm{~N} \mathrm{HCl}$ Figure 5(a). and buffered $\mathrm{pH} 4.5$ Figure 5(b), which depicts the significant difference between the drug $(p \leq 0.05)$. In phosphate buffer $(\mathrm{pH} 6.8)$, no significant difference was observed between the drug Figure 5(c). In multimedia, the inclusion complex showed no significant difference when compared with the HP $\beta C D-b a s e d$ inclusion complex [16]. The multimedia dissolution data show that as the buffer's $\mathrm{pH}$ decreased from 6.8 to 4.5 and 1.2, the dissolution rate was significantly enhanced.

\subsection{Figures, Tables, and Schemes}

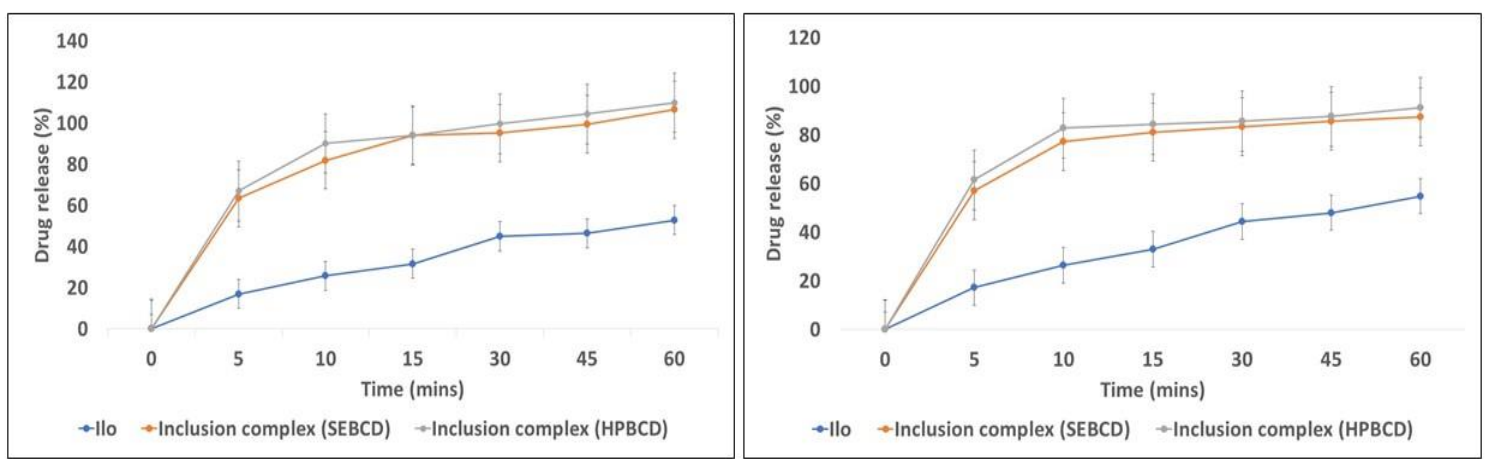

(a)

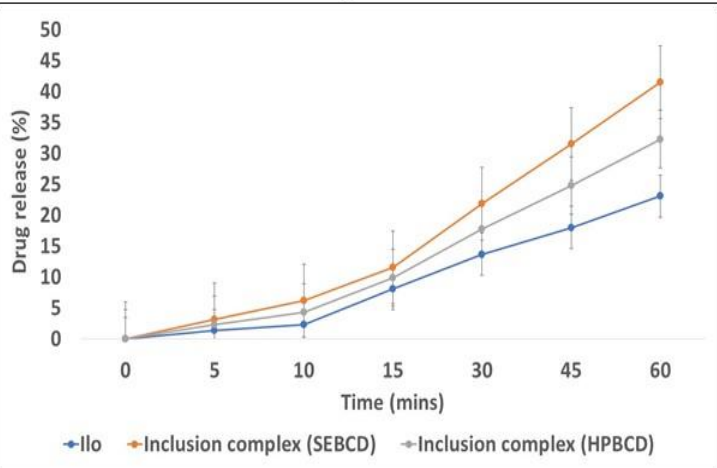

(b)

(c)

Figure 5. Multimedia dissolution (a)pH 1.2 (b)pH 4.5, (c)pH 6.8 of the drug (ILO) and the inclusion complex

$$
(p \leq 0.05, \text { Mean } \pm \mathrm{SD}, \mathrm{n}=3) .
$$

\section{Conclusions}

In this research article, we evaluated the inclusion of SE $\beta C D$ to enhance the solubility of the drug. Thermal analysis (DSC) and FTIR depict the reduction in crystallinity and increase the host-guest interaction, suggesting the inclusion of complex formation. SE $\beta C D$ displayed improved complexation efficacy and solubility and more stability, as detected from the FTIR study. The inclusion complex might be attributed to the enhanced dissolution of the drug. Thus, it can be concluded that SE $\beta C D$-based inclusion complexes can lead to an increase in solubility, which may enhance the drug's bioavailability.

Author Contributions: V.L. and R.B. conceived and designed the experiments; R.B. performed the experiments; V.L. and R.B. analyzed the data; SERB, Cyclolab, Symed lab, and SPP SPTM contributed reagents/materials/analysis tools; R.B. wrote the paper.

Institutional Review Board Statement: Not applicable

Informed Consent Statement: Not applicable 
Data Availability Statement: Exclude this statement

Acknowledgments: This research was supported by the Science and Engineering Research Board, File Number: CRG/2018/003176. The authors would like to acknowledge the help provided by Symed lab and Cyclolab in the form of gift samples.

Conflicts of Interest: The authors declare no conflict of interest.

\section{Abbreviations}

The following abbreviations are used in this manuscript:

$\begin{array}{ll}\text { ILO } & \text { Iloperidone } \\ \text { Se } \beta C D & \text { sulfobutyl ether- } \beta \text {-cyclodextrin } \\ \text { BCS } & \text { Biopharmaceutical Classification Systems } \\ \text { ATR-FTIR } & \text { Attenuated total reflection- Fourier-transform infrared spectroscopy } \\ \text { DSC } & \text { Differential scanning calorimetry } \\ \text { CE } & \text { Complexation efficiency } \\ \text { Kc } & \text { stability constant }\end{array}$

\section{References}

1. Gribbon, P.; Andreas, S. High-throughput drug discovery: What can we expect from HTS? Drug Discov. Today 2005, 1, 17-22.

2. Leuner, C.; Dressman, J. Improving drug solubility for oral delivery using solid dispersions. Eur. J. Pharm. Biopharm. 2000, 50, 47-60.

3. Danel, C.; Azaroual, N.; Chavaria, C.; Odou, P.; Martel, B.; Vaccher, C. Comparative study of the complex forming ability and enantioselectivity of cyclodextrin polymers by CE and 1H NMR. Carbohydr. Polym. 2013, 92, 2282-2292.

4. De Araújo, M.V.G.; Vieira, J.V.F.; Da Silva, C.W.; Barison, A.; Andrade, G.R.S.; Da Costa, N.B.; Barboza, F.M.; Nadal, J.M.; Novatski, A.; Farago, P.V.; et al. Host-guest complexes of 2-hydroxypropyl- $\beta$-cyclodextrin/ $\beta$-cyclodextrin and nifedipine: $1 \mathrm{H}$ NMR, molecular modeling, and dissolution studies. J. Mol. Struct. 2017, 1150, 146-154, doi:10.1016/j.molstruc.2017.08.048.

5. Conceicao, J.; Adeoye, O.; Cabral-Marques, H.M.; Lobo, J. Cyclodextrins as Drug Carriers in Pharmaceutical Technology: The State of the Art. Curr. Pharm. Des. 2018, 24, 1405-1433.

6. Kim, C.-K.; Park, J.-S. Solubility Enhancers for Oral Drug Delivery. Am. J. Drug Deliv. 2004, 2, 113-130.

7. iloperidone-U.S. Food and Drug Administration Search Results [Internet]. Search.usa.gov. 2020. Available online: https://search.usa.gov/search?query=iloperidone\&affiliate=fda1 (accessed on 20 May 2020).

8. Weiden, P.J. Iloperidone for the Treatment of Schizophrenia: An Updated Clinical Review. Clin. Schizophr. Relat. Psychoses 2012, 6, 34-44, doi:10.3371/csrp.6.1.5.

9. Breier, A.; Berg, P.H. The psychosis of schizophrenia: Prevalence, response to atypical antipsychotics, and prediction of outcome. Biol. Psychiatry 1999, 46, 361-364, doi:10.1016/s0006-3223(99)00040-2.

10. Cheng, Y.-H.; Illum, L.; Davis, S.S. Schizophrenia and Drug Delivery Systems. J. Drug Target. 2000, 8, 107-117, doi:10.3109/10611860008996856.

11. Londhe, V.Y.; Shirsat, R. Formulation and Characterization of Fast-Dissolving Sublingual Film of Iloperidone Using BoxBehnken Design for Enhancement of Oral Bioavailability. AAPS PharmSciTech 2018, 19, 1392-1400, doi:10.1208/s12249-018-0954y.

12. Soniwala, M.M.; Patel, P.R.; Ansuri, M.S.; Parikh, R.K.; Goel, M.C. Various approaches in dissolution enhancement of Rofecoxib. Indian J. Pharm. Sci. 2005, 67, 61-63.

13. Kim Y.; Oksanen, A.D.; Massefski, W., Jr., Blake, F.J.; Duffy, M.E.; Chrunyk, B. Inclusion complexation of ziprasidone mesylate with b-cyclodextrin sulfobutyl ether. J. Pharm. Sci. 1998, 87, 1560-1567.

14. Patel, M.; Hirlekar, R. Multicomponent cyclodextrin system for improvement of solubility and dissolution rate of poorly water soluble drug. Asian J. Pharm. Sci. 2019, 14, 104-115, doi:10.1016/j.ajps.2018.02.007.

15. Xu, J.; Zhang, Y.; Li, X.; Zheng, Y. Inclusion complex of nateglinide with sulfobutyl ether b-cyclodextrin: Preparation, characterization and water solubility. J. Mol. Struct. 2017, 1141, 328-334.

16. Londhe, V.Y.; Pawar, A.; Kundaikar, H. Studies on spectral characterization and solubility of hydroxypropyl $\beta$-cyclodextrin/iloperidone binary and ternary complexes using different auxiliary agents. J. Mol. Struct. 2020, 1220, 128615, doi:10.1016/j.molstruc.2020.128615. 